\title{
SPEED-STRENGTH RELATIONSHIP BETWEEN ROWING ON ERGOMETER AND CLEAN PULL EXERCISE
}

\author{
Oleg Hristov
}

National Sports Academy "Vassil Levski", Sofia, Bulgaria

\begin{abstract}
Speed-strength qualities are significant for obtaining high power, especially in sports such as rowing. There are few surveys quoted in literature on multi-joint movements with increasing load in the training and competitive range of intensity where the speed-strength qualities are traced. In our research, we aim to make a comparative analysis of speed-strength qualities with increasing load in two multi-joint exercises: rowing on rowing ergometer and the clean pull strength exercise. The research was conducted among rowers ( $n=7$; age - $16.28 \pm 1.11$ years; weight $-73.12 \pm 7.63 \mathrm{~kg}$; height $-186.27 \pm 7.20 \mathrm{~cm}$ ). The test on a rowing ergometer was performed with Concept II Model C, and the data were processed with the system BioRowTech. The data from the strength exercise were recorded and processed with the system GymAwareCloud. Regression equations were worked out for the speed-strength qualities: in clean pull exercisepeak force $R^{2}=0.52$ and average force $R^{2}=0.76$; in rowing on ergometer - peak force $R^{2}=0.72$ and average force $R^{2}=0.56$. We found out that in both exercises the mean power reached was almost identical (in rowing $=692.28 \mathrm{~W}$, in clean pull $=609.42 \mathrm{~W}$ ), but in rowing it is on account of higher velocity and less force.
\end{abstract}

Key words: speed-strength, rowing, clean pull, different loads

\section{INTRODUCTION}

Everybody who has some experience in the field of biomechanics and physiology is aware of the relationship between force and velocity as a result of the actions of the skeletal muscles. The research in this area was greatly developed at the end of the $20^{\text {th }}$ century, starting with Hill (1922), Gasser and Hill (1924), Hill (1938), Katz (1939) and still continuing today. The surveys in this direction can be divided into three groups: 1) single fibers / single muscles, 2) single-joint movement, 3) multijoint movement.

The surveys in the first direction of studies are related mostly to the shape of the curve expressing the relation force-velocity, as well as the factors which influence it, namely: type of muscle fibers (Baratta et al., 1995), type of stimulation (Heckman et al., 1992), fatigue
(Ameredes et al., 1992), temperature (Assmussen et al., 1994), etc.

The surveys on single-joint movements allow research of human muscles which lead to change in the movement only of one joint, while the rest of the body is static during the maximal effort. The most numerous studies found in literature concern the following joints: elbow (Wilkie, 1950; Martin et al., 1995), knee (Johanson et al., 1987; Seger and Throstensson, 2000), ankle (Bobbert et al., 1990). Most of the researchers claim that the obtained curve of the relation between force and velocity is similar to the one introduced by Hill.

The characteristics of speed-strength qualities in multi-joint movements are relatively understudied compared to the relationships in single muscles and single-joint movements. A number of authors study the relationship 
velocity-force in pedaling on a stationary bike (Baron et al., 1999), weight lifting (Thomas et al., 1996), vertical jump (Bosco and Komi, 1979). There are some surveys done in this direction with rowing ergometer (Hartmann et al., 1993; Sprague et al., 2007) where the relationship force-velocity in several maximum cycles (5-6) was studied.

Multi-joint movements are characterized with additional complications because a number of muscles and muscle groups work together and move in certain coordination pattern. Therefore, when studying multijoint movements, we have to measure and analyze the force and velocity throughout their action. With these movements, the nervous agitation and the influence of the different muscles is constantly changing during the execution of the whole movement. This is particularly important, since it is presumed that the mechanical features of the muscle systems acting in a multi-joint motor task may differ from the mechanical features of the different muscles.

Rowing is a kind of sport where the execution of a stroke cycle is performed by almost all muscles in the human body, and lots of authors (Christov, Christov, 1989; Christov, 1997; Kleshnev, 2000; Soper\&Hume, 2004; Notle, 2011) define this activity as working with three segments - lower limbs, torso and upper limbs. The standard consequence of activities during the work phase of the stroke cycle of these segments is: lower limbs followed by the torso, and finally - upper limbs. There are some data in literature about the power of a stroke cycle, peak power in a stroke cycle, mean and maximum force applied to the oar handle, as well as some limited data about the velocity of the handle during realization of this strength (Christov, 1988; Bourdin et al., 2004; Kleshnev, 2000; Soper\&Hume, 2004). There are no data concerning velocity-force indexes from tests with a progressive increase in intensity which could provide information about the work regime of muscle groups in different types of intensity used in the training programs.

In order to increase the level of strength preparation in rowing, strength exercises on land are regularly performed with different methods and means but most often with barbells. One of the complex exercises used is the clean pull because it combines the work of the above mentioned three segments: lower limbs, torso and upper limbs in close or identical sequence to the stroke cycle (Bachev, 1987; Bachev et al., 2000).

Hence, the aim of this research was to study the relation velocity-force and to make a comparative analysis of two similar in the structure of performance multi-purpose tasks connected with multi-joint activity, namely rowing on ergometer and clean pull.

\section{METHODOLOGY}

Seven young rowers on national level of preparation took part in the research (age $16.28 \pm 1.11$ years; weight $73.12 \pm 7.63 \mathrm{~kg}$; height $186.27 \pm 7.20 \mathrm{~cm}$ ). They participated in a-two-day survey on rowing ergometer and undertook a test for strength preparation (clean pull). During the first day the test on the rowing ergometer was performed, and on the second day the clean pull test was carried out.

The research on rowing ergometer was done with Concept II Model C, and the velocity-force indexes were measured with the help of Bio Row Techequipment (http:// biorow.com/index.php?route=product/ product\&path $=61 \_108 \&$ product_id $=60$ ). The force in the handle was measured with a strength amount with work range (a range of $0-2500 \mathrm{~N}$, with the accuracy being within $0.4 \%$ of the range). The velocity of the handle was measured directly with linear positional 
transducer, which is connected to the handle with a cord. Each competitor performed 10 cycles with different intensity - number of cycles per minute: $16 ; 20 ; 24 ; 28 ; 32$ cycle/ min, which ranged between low training intensity to competitive intensity for rowing ergometer. Each intensity was performed with two-min breaks in between every activity. After the recorded data were processed with the software, the average values for each intensity were obtained. The following indexes of the movement of the handle were measured: maximum force $[\mathrm{N}]$; average force $[\mathrm{N}]$, maximum velocity $[\mathrm{m} / \mathrm{s}]$, average velocity $[\mathrm{m} / \mathrm{s}]$, peak power [W], average power [W], length of a stroke cycle [m].

The velocity-force indexes in the clean pull exercise were measured with the system Gym Aware of Kinetic Performance and the data were processed with online software Gym Aware Cloud. It is important to point out that with this equipment the speed of the barbell is measured along the same principle as the speed of the ergometer handle measured with a linear positional transducer. A classic test for determining the maximum force was performed (Jovanovic et al., 2014). The test started with $20 \mathrm{~kg}$ weight and the subsequent weights were increased with $10 \mathrm{~kg}$ each until reaching the individual maximum for every participant. The competitors' personal weight was not included in the calculation of the derivative indexes from the test. There was a sufficient resting time between each performance during the test (a minimum of $5 \mathrm{~min}$ ). On the base of a directly measured force and preliminarily set weight of the barbell the following parameters for each weight of the load were calculated: peak force $[\mathrm{N}]$; average force $[\mathrm{N}]$, peak velocity $[\mathrm{m} / \mathrm{s}]$, average velocity $[\mathrm{m} / \mathrm{s}]$, peak power [W], average power [W], height of the barbell pull [m].

\section{RESULTS}

The obtained results were statistically processed with variation and correlation analyses. All parameters had a normal distribution of the values compared to the critical ones for number of attempts. In the correlation analysis, between the parameters recorded for the two exercises, we obtained values between 0.706 and 0.977 with significance level $\mathrm{Sig}=0.00$, which shows a high $(0.7-0.9)$ and very high correlation ( $>0.9$ ) between them.

Sample graph illustrations are presented in Figures 1 and 2, and the average values along the loads of all researched individuals in Table 1 and Table 2.
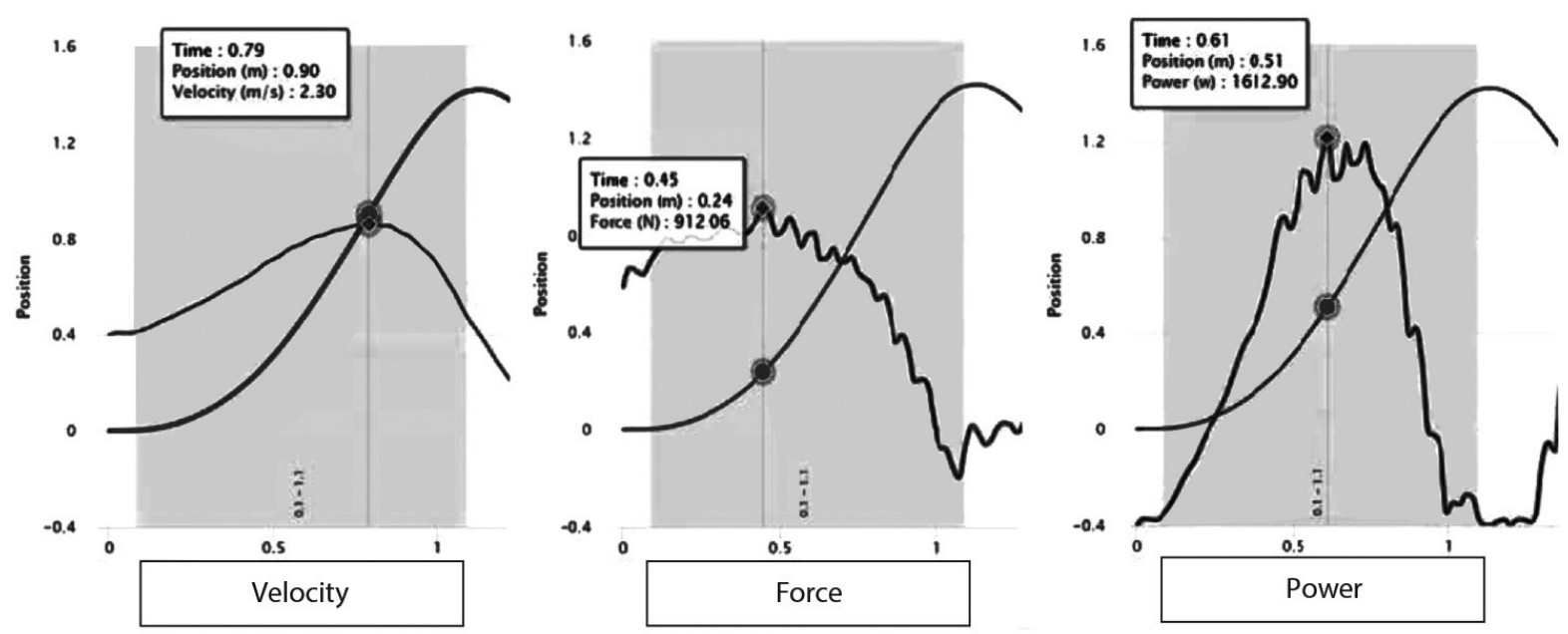

Figure 1. Sample graph of a certain attempt "clean pull” obtained with Gym Aware Cloud. 

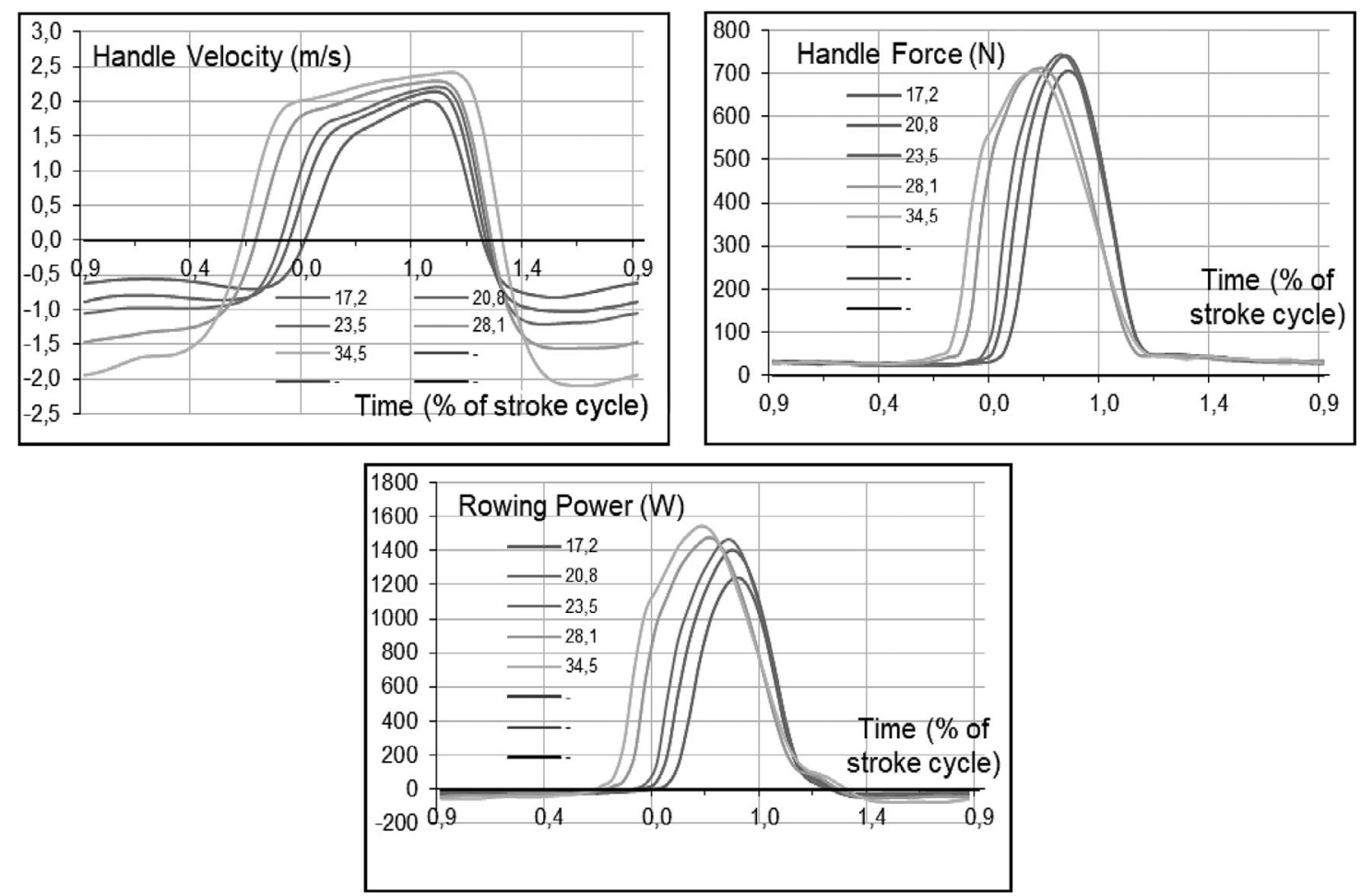

Figure 2. Sample graph of a certain competitor of the average stroke cycles in all kinds of intensity on a rowing ergometer obtained with BioRowTech.

In the sample graphs of velocity, force and power in Figures 1 and 2 indicate that these two exercises are almost identical as regards their features and parameters. The velocity in both exercises starts from zero and its maximum values are reached in the second half of the activity. The development of force reaches its maximum before the middle of the activity.

The comparative analysis of the average results from the two tests established the fol- is significantly greater. lowing:

significantly greater.

The work amplitude is different - on a rowing ergometer it is $1.62 \mathrm{~m}$ with variation $0.9 \%$, while in the clean pull exercise it is $1.19 \mathrm{~m}$ with variation $8.3 \%$. This difference is observed due to the fact that in the clean pull the wrists cannot reach the level of the feet because the diameter of the barbell plate obstructs them. While in rowing, the wrists (the handle) go over the feet and so the amplitude

Table 1. Average results of the parameters from clean pull $n=7$

\begin{tabular}{|c|c|c|c|c|c|c|c|c|c|c|c|c|c|c|}
\hline \multirow[b]{2}{*}{$\begin{array}{c}\text { Weight } \\
\text { (kg) }\end{array}$} & \multicolumn{2}{|c|}{$\begin{array}{c}\text { Height } \\
\text { Average(m) }\end{array}$} & \multicolumn{2}{|c|}{$\begin{array}{c}\text { Mean } \\
\text { Power (W) }\end{array}$} & \multicolumn{2}{|c|}{$\begin{array}{c}\text { Peak } \\
\text { Power (W) }\end{array}$} & \multicolumn{2}{|c|}{$\begin{array}{c}\text { Mean } \\
\text { Velocity } \\
(\mathrm{m} / \mathrm{s})\end{array}$} & \multicolumn{2}{|c|}{$\begin{array}{c}\text { Peak } \\
\text { Velocity } \\
(\mathbf{m} / \mathbf{s})\end{array}$} & \multicolumn{2}{|c|}{$\begin{array}{c}\text { Mean Force } \\
\text { (N) }\end{array}$} & \multicolumn{2}{|c|}{$\begin{array}{c}\text { Peak } \\
\text { Force }(\mathrm{N})\end{array}$} \\
\hline & $\begin{array}{l}\text { Valu- } \\
\text { es }\end{array}$ & $\begin{array}{c}\text { ST } \\
\text { DEV }\end{array}$ & $\begin{array}{l}\text { Valu- } \\
\text { es }\end{array}$ & $\begin{array}{c}\text { ST } \\
\text { DEV }\end{array}$ & $\begin{array}{l}\text { Valu- } \\
\text { es }\end{array}$ & $\begin{array}{c}\text { ST } \\
\text { DEV }\end{array}$ & $\begin{array}{l}\text { Valu- } \\
\text { es }\end{array}$ & $\begin{array}{c}\text { ST } \\
\text { DEV }\end{array}$ & $\begin{array}{l}\text { Valu- } \\
\text { es }\end{array}$ & $\begin{array}{c}\text { ST } \\
\text { DEV }\end{array}$ & $\begin{array}{l}\text { Valu- } \\
\text { es }\end{array}$ & $\begin{array}{c}\text { ST } \\
\text { DEV }\end{array}$ & $\begin{array}{l}\text { Valu- } \\
\text { es }\end{array}$ & $\begin{array}{c}\text { ST } \\
\text { DEV }\end{array}$ \\
\hline 20.00 & 1.29 & \pm 0.1 & 415.6 & \pm 59.5 & 1013.4 & \pm 183.7 & 1.85 & \pm 0.1 & 3.17 & \pm 0.3 & 204.3 & \pm 6.4 & 467.2 & \pm 54.7 \\
\hline 30.00 & 1.29 & \pm 0.1 & 552.6 & \pm 88.4 & 1233.1 & \pm 220.3 & 1.71 & \pm 0.2 & 2.86 & \pm 0.3 & 307.8 & \pm 5.3 & 632.7 & \pm 114.4 \\
\hline 40.00 & 1.25 & \pm 0.1 & 619.3 & \pm 104.6 & 1313.7 & \pm 256.9 & 1.52 & \pm 0.2 & 2.48 & \pm 0.4 & 404.2 & \pm 10.7 & 755.8 & \pm 128.9 \\
\hline 50.00 & 1.20 & \pm 0.1 & 654.7 & \pm 122.4 & 1338.1 & \pm 226.9 & 1.31 & \pm 0.2 & 2.18 & \pm 0.3 & 501.5 & \pm 6.7 & 808.1 & \pm 54.7 \\
\hline 60.00 & 1.11 & \pm 0.2 & 631.9 & \pm 133.9 & 1291.7 & \pm 205.5 & 1.07 & \pm 0.2 & 1.85 & \pm 0.3 & 598.5 & \pm 5.1 & 885.2 & \pm 87.5 \\
\hline 70.00 & 1.11 & \pm 0.1 & 725.2 & \pm 106.8 & 1373.2 & \pm 196.8 & 1.05 & \pm 0.2 & 1.72 & \pm 0.2 & 696.9 & \pm 4.0 & 968.8 & \pm 42.9 \\
\hline 80.00 & 1.04 & \pm 0.1 & 666.8 & \pm 103.8 & 1417.3 & \pm 153.2 & 0.85 & \pm 0.1 & 1.56 & \pm 0.2 & 796.7 & \pm 4.0 & 1044.2 & \pm 30.1 \\
\hline Avr. & \multicolumn{2}{|c|}{1.19} & \multicolumn{2}{|c|}{609.42} & \multicolumn{2}{|c|}{1282.94} & \multicolumn{2}{|c|}{1.34} & \multicolumn{2}{|c|}{2.26} & \multicolumn{2}{|c|}{501.40} & \multicolumn{2}{|c|}{794.57} \\
\hline STDEV & \multicolumn{2}{|c|}{0.10} & \multicolumn{2}{|c|}{100.13} & \multicolumn{2}{|c|}{132.52} & \multicolumn{2}{|c|}{0.37} & \multicolumn{2}{|c|}{0.61} & \multicolumn{2}{|c|}{212.15} & \multicolumn{2}{|c|}{198.29} \\
\hline $\begin{array}{c}\text { Variation } \\
\%\end{array}$ & \multicolumn{2}{|c|}{$8.3 \%$} & \multicolumn{2}{|c|}{$16.4 \%$} & \multicolumn{2}{|c|}{$10.3 \%$} & \multicolumn{2}{|c|}{$27.8 \%$} & \multicolumn{2}{|c|}{$26.8 \%$} & \multicolumn{2}{|c|}{$42.3 \%$} & \multicolumn{2}{|c|}{$25.0 \%$} \\
\hline
\end{tabular}


The values of the speeds of the execution of the exercises differ in the average values on rowing ergometer the velocity is $1.66 \mathrm{~m} / \mathrm{s}$ with variation $13.4 \%$, starting from $1.37 \mathrm{~m} /$ sand ending to $1.93 \mathrm{~m} / \mathrm{s}$ in the range of intensity increase. While the average value of velocity in clean pull is $1.34 \mathrm{~m} / \mathrm{s}$ with variation $27.8 \%$ and initial speed of the slightest load $1.85 \mathrm{~m} / \mathrm{s}$ to the toughest load of $0.85 \mathrm{~m} / \mathrm{s}$. It can be observed that the range of velocity change in the two exercises is different: in rowing it is $0.56 \mathrm{~m} / \mathrm{s}$, while in clean pull it is $1.00 \mathrm{~m} / \mathrm{s}$. The reached maximum values are close, and the differences are observed in the minimum values - almost 50\% lower. It should be pointed out that in rowing, with the small load the velocity is the lowest, and with the increase in the intensity it grows. While in the strength exercise, with the small load the velocity is the highest, and with the increase in the intensity it begins to decrease - a classic reaction for speed-strength relation.

Table 2. Average results from 10 stroke cycles on ergometer $n=7$.

\begin{tabular}{|c|c|c|c|c|c|c|c|c|c|c|c|c|c|c|}
\hline \multirow[b]{2}{*}{$\begin{array}{c}\text { Stroke } \\
\text { Rate (str/ } \\
\text { min) }\end{array}$} & \multicolumn{2}{|c|}{$\begin{array}{c}\text { Stroke } \\
\text { Length (m) }\end{array}$} & \multicolumn{2}{|c|}{$\begin{array}{c}\text { Mean } \\
\text { Power (W) }\end{array}$} & \multicolumn{2}{|c|}{$\begin{array}{c}\text { Peak } \\
\text { Power (W) }\end{array}$} & \multicolumn{2}{|c|}{$\begin{array}{c}\text { Mean } \\
\text { Handle } \\
\text { Velocity }(\mathrm{m} / \mathrm{s})\end{array}$} & \multicolumn{2}{|c|}{$\begin{array}{c}\text { Peak } \\
\text { Handle } \\
\text { Velocity }(\mathrm{m} / \mathrm{s})\end{array}$} & \multicolumn{2}{|c|}{$\begin{array}{c}\text { Mean } \\
\text { Handle Force } \\
\text { (N) }\end{array}$} & \multicolumn{2}{|c|}{$\begin{array}{c}\text { Peak } \\
\text { Handle Force } \\
\text { (N) }\end{array}$} \\
\hline & $\begin{array}{l}\text { Valu- } \\
\text { es }\end{array}$ & $\begin{array}{c}\text { ST } \\
\text { DEV }\end{array}$ & $\begin{array}{l}\text { Valu- } \\
\text { es }\end{array}$ & $\begin{array}{c}\text { ST } \\
\text { DEV }\end{array}$ & $\begin{array}{l}\text { Valu- } \\
\text { es }\end{array}$ & $\begin{array}{c}\text { ST } \\
\text { DEV }\end{array}$ & $\begin{array}{l}\text { Valu- } \\
\text { es }\end{array}$ & $\begin{array}{c}\text { ST } \\
\text { DEV }\end{array}$ & $\begin{array}{l}\text { Valu } \\
\text { es }\end{array}$ & $\begin{array}{c}\text { ST } \\
\text { DEV }\end{array}$ & $\begin{array}{l}\text { Valu } \\
\text { es }\end{array}$ & $\begin{array}{c}\text { ST } \\
\text { DEV }\end{array}$ & $\begin{array}{l}\text { Valu } \\
\text { es }\end{array}$ & $\begin{array}{c}\text { ST } \\
\text { DEV }\end{array}$ \\
\hline 16.70 & 1.60 & \pm 0.1 & 539.5 & \pm 24.6 & 1204.3 & \pm 180.4 & 1.37 & \pm 0.1 & 2.00 & \pm 0.1 & 336.8 & \pm 36.5 & 712.6 & \pm 111.1 \\
\hline 20.21 & 1.63 & \pm 0.1 & 594.0 & \pm 36.1 & 1309.0 & \pm 267.5 & 1.51 & \pm 0.1 & 2.14 & \pm 0.1 & 344.7 & \pm 48.0 & 738.8 & \pm 124.5 \\
\hline 24.22 & 1.63 & \pm 0.1 & 691.9 & \pm 36.9 & 1563.7 & \pm 167.7 & 1.67 & \pm 0.1 & 2.31 & \pm 0.1 & 368.3 & \pm 44.5 & 796.9 & \pm 104.2 \\
\hline 28.71 & 1.62 & \pm 0.1 & 760.6 & \pm 59.9 & 1710.7 & \pm 262.3 & 1.80 & \pm 0.1 & 2.45 & \pm 0.1 & 382.4 & \pm 55.6 & 824.8 & \pm 140.4 \\
\hline 32.91 & 1.60 & \pm 0.1 & 875.5 & \pm 86.4 & 2004.9 & \pm 277.0 & 1.93 & \pm 0.1 & 2.60 & \pm 0.2 & 414.4 & \pm 69.7 & 894.8 & \pm 163.0 \\
\hline Avr. & \multicolumn{2}{|c|}{1.62} & \multicolumn{2}{|c|}{692.28} & \multicolumn{2}{|c|}{1558.51} & \multicolumn{2}{|c|}{1.66} & \multicolumn{2}{|c|}{2.30} & \multicolumn{2}{|c|}{369.30} & \multicolumn{2}{|c|}{793.58} \\
\hline STDEV & \multicolumn{2}{|c|}{0.01} & \multicolumn{2}{|c|}{133.46} & \multicolumn{2}{|c|}{320.21} & \multicolumn{2}{|c|}{0.22} & \multicolumn{2}{|c|}{0.24} & \multicolumn{2}{|c|}{31.09} & \multicolumn{2}{|c|}{72.10} \\
\hline $\begin{array}{c}\text { Variation } \\
\% \\
\end{array}$ & \multicolumn{2}{|c|}{$0.9 \%$} & \multicolumn{2}{|c|}{$19.3 \%$} & \multicolumn{2}{|c|}{$20.5 \%$} & \multicolumn{2}{|c|}{$13.4 \%$} & \multicolumn{2}{|c|}{$10.4 \%$} & \multicolumn{2}{|c|}{$8.4 \%$} & \multicolumn{2}{|c|}{$9.1 \%$} \\
\hline
\end{tabular}

The strength parameters recorded during the execution of the two exercises show no difference in their maximum values, only in the minimum ones. The average value of the force in rowing on ergometer is $369.30 \mathrm{~N}$ with variation $8.4 \%$, and in the strength exercise clean pull, it is $501.40 \mathrm{~N}$ with variation $42.3 \%$. The force in the smallest weight in clean pull is $204.3 \mathrm{~N}$, which makes it the lowest; with an increase in the weight there is a growth in the applied force until reaching its maximum value of $796.7 \mathrm{~N}$. In rowing on ergometer, at the lowest intensity the lowest force is observed, namely $336.8 \mathrm{~N}$, while at the highest intensity the force is the greatest with $414.4 \mathrm{~N}$.

As a result of this activity, the power is presented in two parameters: mean power and peak power. The mean value of the power in rowing on ergometer for a stroke cycle is $692.28 \mathrm{~W}$ with variation $19.3 \%$, while in the strength exercise it is $609.42 \mathrm{~W}$ with variation $16.4 \%$, which is about $12 \%$ higher power in rowing. The peak values of power show significantly higher values in the test on a rowing ergometer and average $1558.5 \mathrm{~W}$ with variation $20.5 \%$, while in the strength test the peak values of power average $1282.9 \mathrm{~W}$ with variation of $10.3 \%$. The significant increase in the peak value of the rowing power is a result of the fact that with an increase in the intensity, the speed significantly rises while the strength component remains relatively stable. While as regards force, despite the increase in the load (strength), the velocity drops abruptly.

A major task of our research was to establish the relation between velocity and force in 
the two tests. For this purpose, we worked out peak force in clean pull $y=-235.81+1325.7$, regression equations of these relationships, $R^{2}=0.52$, mean force in clean pull $y=$ which are the following: peak force in rowing $-455.81+1107.7, R^{2}=0.7594$. A graphic illus$y=357.52+57.924, R^{2}=0.7214$; mean force tration of these relationships and their regresin rowing $y=148.13+109.98, R^{2}=0.5614$; sion equations is shown in Figure 3 .

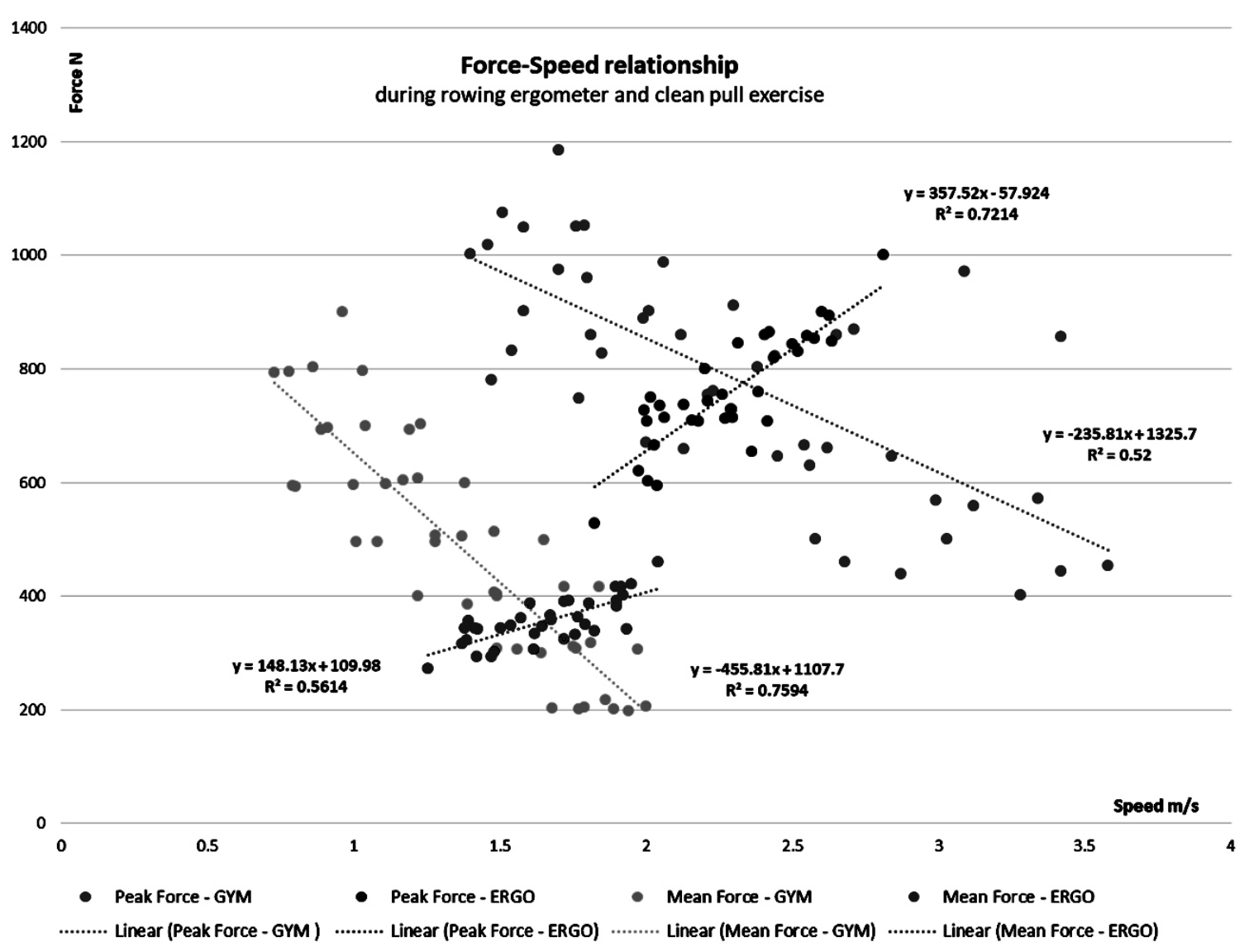

Figure 3. Strength-speed relationships in mean and peak values of test on rowing ergometer and strength test clean pull

Figure 3, Tables 1 and 2, show the average values of speed-strength relationships in the two tests, the observations are the following: in rowing on ergometer the power is within $40-50 \%$ of the maximum force in the strength test and in the high border values of the velocity reached - almost $100 \%$ or about $2 \mathrm{~m} / \mathrm{s}$. While with the peak values, the rowers perform the stroke cycle with 60 $-80 \%$ of the peak force values and $80-90 \%$ of the speed indexes established from the test clean pull.

Graphs also show that, in rowing when the intensity is increased, the force and velocity of muscle exertion also increase both in the mean and peak values. Their regression equations are with a positive sign in front of the independent variable (x), and in the equations for the strength test they are with a negative sign.

\section{CONCLUSION}

The research on a rowing ergometer and the strength exercise clean pull with increasing load shows that the velocity-force relationship in rowing has a reversed trend compared to the normally established one by Hill in strength exercises. The regression equations in rowing, both in the mean 
and in the peak value have a positive sign in front of the independent variable (x) which predetermines the fact that when the speed is increased, the strength of the muscle contraction also increases. In the strength test we found a normal linear interdependence between force and velocity, where with the increase in speed, the strength decreases.

The analysis of the results shows that the reached mean power, which is the more important index in the two exercises, is almost the same but is a product of different velocityforce relations. In the strength test it is a result of the greater value of the force and low velocity of the muscle contraction, while in rowing it is a product of a relatively low value of the force and high velocity ranging from $1.2 \mathrm{~m} / \mathrm{s}$ to almost $3.0 \mathrm{~m} / \mathrm{s}$ (Figure 3 ).

These results should reflect on the analysis of the training methods for speed-strength qualities of rowers. A significant attention needs to be paid to the increase in the speed component of this quality at the presence of high strength potential.

The research findings provoke a discussion related to the difference between the strength-speed curves obtained in rowing ergometer and the classical curve of Hill. In our opinion, this difference is due to the nature and specificity of the motor action. For example, Assmussen et al., 1994, Seger and Throstensson, 2000, Martin, et al., 1995 carried out their research on muscle contraction exercises, as a result of concentric effort to overcome certain resistance or gravity and obtained a force-velocity curve resembling that of Hill. In exercises like ours, where the muscle effort is in one or multi joined movements, a certain resistance is also overcome. We assumed that this leads to an increase in the speed (movement, turnovers) of the object on which the effort is applied. In this situation, at every subsequent progressive effort, the object is driven at an increasing speed. So here we see increasing power on account of the speed component, which was also confirmed by Baron et al., 1999, Newton et al., 1997, Arsac et al., 1995; Thomas, et al., 1996. In conclusion, we think that more in-depth research is needed on variety of exercises related to similar of ergometer propulsion.

\section{REFERENCES}

Ameredes, B. T., Brechue, W. F., Andrew, G.M. and Stainsby, W. N. (1992). Force velocity shifts with repetitive isometric and isotonic contractions of canine gastrocnemius in situ. Journal of Applied Physiology. 73, pp. 21052111.

Arsac, L. M., Hautier, C. A., Lacour, J. R. and Belli, A. (1995) Effect of sprint training on a cycle ergometer on the muscle power-velocity measured during cycling. XVth Congress of the International Society of Biomechanics. (Edited by Hakkinen, K., Keskinen, K. L., Komi, P. V. and Mero, A.), pp. 70-71. Jyvaskyla, Finland.

Assmussen, G., Beckers-Bleukx, G., and Marechal, G. (1994). The force-velocity relation of the rabbit inferior oblique muscle; influence of temperature. Pflugers Archives. 426, pp. 542-547.

Bachev, V. (1987). „Fizicheska podgotovka v grebaneto", monography // Бачев, В. (1987). „Физическа подготовка в гребането”, монография.

Bachev, V., Oronova, D., Kaloupsis, B., Neikov, Sv. (2004). Sredstva za silova podgotovka v grebaneto. Sport and Science. pp. 4 // Бачев, В., Оронова, Д., Калоуписис, Б., Нейков, Св. (2004). Средства за силова подготовка в гребането. Спорт и наука. стр. 4.

Baratta, R. V., Solomonow, M., Best, R., Zembo, M., and D'Ambrosia, R. (1995). 
Force-velocity relations of nine load-moving skeletal muscles. Medical and Biological Engineering and Computing.33, pp. 537-564.

Baron, R., Bachl, N., Petschnig, R., Tschan, H., Smekal, G. and Pokan, R. (1999). Measurement of maximal power output in isokinetic and non-isokinetic cycling. A comparison of two methods. International Journal of Sports Medicine. 20, 532-537.

Bobbert, M. F. and Ingen Schenau, G. J. van. (1990). Isokinetic plantar flexion: experimental results and model calculations. Journal of Biomechanics. 23, pp. 105-119.

Bosco, C. and Komi, P. V. (1979). Potentiation of the mechanical behavior of the human skeletal muscle through pre stretching. Acta Physiologica Scandinavica.106, pp. 467-472.

Bourdin, M, Messonnier, L, Hager, JP, Lacour JR. (2004). Peak power output predicts rowing ergometer performance in elite male rowers. Int J Sports Med 25(5): pp. 368373.

Christov, R. (1997). „About percentage activity and the characteristic function of the muscle groups" - FISA Coaches 'Conference, Plovdiv. Rowing and Bulgarian sport science

Christov, R., Christov, R., Zdravkov, N. (1988). „Selection and testing system based on biomechanical studies in racing boats and on rowing ergometer" 17. FISA Coaches' Conference - Limerick, Ireland

Christov, T. R., Christov, R. (1989). „Kraft training Im Rudern - vom isometrische zum izokinetischen" - RUDER SPORT 03.

Gasser, H. S. and Hill, A. V. (1924). The dynamic of muscular contraction. Proceedings of the Royal Society of London B. 96, pp. 398-437.

Hartmann, U., Mader, A., Wasser, K. and Klauer, I. (1993). Peak force, velocity, and power during five and ten maximal rowing ergometer strokes by world class female and male rowers. International Journal of Sports
Medicine. 14, pp. S42-S45.

Heckman, C. J., Weytjens, J. L. And Loeb, G. E. (1992). Effect of velocity and mechanical history on the forces of motor units in the catmedial gastrocnemius muscle. Journal of Neurophysiology. 68, pp. 1503-1515.

Hill, A. V. (1922). The maximum work and mechanical efficiency of human muscles, and their most economical speed. Journal of Physiology. 56, pp. 19-41.

Hill, A. V. (1938). The heat of shortening and the dynamic constants of muscle. Proceedings of the Royal Society of London, B. 126, pp. 136-195.

Johansson, C., Lorentzon, R., Sjostrom, M., Fagerlund, M. and Fugl-Meyers, A. R. (1987). Sprinters and Marathon Runners. Does isokinetic knee extensor performance reflect muscle size and structure? Acta Physiologica Scandinavica. 130, pp. 663-669.

Jovanovic, M. and Eamonn P., Flanagan. (2014). Researched Applications of Velocity Based Strength Training. Journal of Australian Strength and Conditioning, 22(2), pp. 58-69

Katz, B. (1939). The relation between force and speed in muscular contraction. Journal of Physiology. 96, pp. 45-64.

Kleshnev, V. (2000). Power in rowing. In Y. Hong (Ed.) Proceedings of XVIII International Symposium on Biomechanics in Sports, Perth, pp. 224-228.

Martin, A., Martin, L. and Morlon, B. (1995). Changes induced by eccentric training on force-velocity relationships of the elbow flexor muscles. European Journal of Applied Physiology. 72, pp. 183-185.

Newton, R. U., Murphy, A. J., Humphries, B. J., Wilson, G. J., Kraemer, W. J. and Hakkinen, K. (1997) Influence of load and stretch shortening cycle on the kinematics, kinetics and muscle activation that occurs during explosive upper body movements. European Journal of 
Applied Physiology. 75, pp. 333-342.

Seger, J. Y. and Thorstensson, A. (2000). Electrically evoked eccentric and concentric torque-velocity relationships in human knee extensor muscles. Acta Physiologica Scandinavica.169, pp. 63-69.

Soper, C., \&Hume, P. (2004). Towardsan Ideal Rowing Technique for Performance: The Contributions from Biomechanics. Sports Medicine, 34(12), pp. 825-848

Sprague, R. C. 4th, Martin J. C., Davidson C.J., Farrar R.P. (2007). Force-velocity and power-velocity relationships during maximal short-term rowing ergometry. MedSci Sports Exerc 39(2): pp. 358-364

Thomas, M., Fiatarone, M. A. and Fielding, R. A. (1996). Leg power in young women: relationship to body composition, strength and function. Medicine and Science in Sports and Exercise. 28, pp. 1321-1326.

Wilkie, D. R. (1950). The relation between force and velocity in human muscle. Journal of Physiology. 110, pp. 249-280.

\section{Corresponding author:}

Oleg Hristov

Centre of Science and Applied Research in Sport

National Sports Academy „Vassil Levski”

Studentski grad, 21, Acad. Stefan Mladenov str.

Sofia 1700, Bulgaria

E-mail: hristov.oleg@gmail.com 